\title{
Glutathione and glutathione peroxidase expression in breast cancer: An immunohistochemical and molecular study
}

\author{
BRUNA VICTORASSO JARDIM ${ }^{1,2}$, MARINA GOBBE MOSCHETTA ${ }^{2,3}$, CAMILA LEONEL $^{1,2}$, \\ GABRIELA BOTTARO GELALETI ${ }^{1,2}$, VITOR RAFAEL REGIANI ${ }^{2}$, LÍVIA CARVALHO FERREIRA ${ }^{1,2}$, \\ JULIANA RAMOS LOPES ${ }^{1,2}$ and DEBORA AP. PIRES DE CAMPOS ZUCCARI ${ }^{2,3}$ \\ ${ }^{1}$ Department of Biology, Sao Paulo State University - UNESP/IBILCE; ${ }^{2}$ Department of Molecular Biology, \\ Laboratory of Molecular Research in Cancer (LIMC), Faculty of Medicine of Sao Jose do Rio Preto (FAMERP); \\ ${ }^{3}$ Department of Molecular Biology, Faculty of Medicine of Sao Jose do Rio Preto (FAMERP), \\ 15090-000 São José do Rio Preto, SP, Brazil
}

Received February 20,2013; Accepted April 18, 2013

DOI: $10.3892 /$ or.2013.2540

\begin{abstract}
The use of prognostic markers for breast cancer allows therapeutic strategies to be defined more efficiently. The expression of glutathione (GSH) and glutathione peroxidase (GPX) in tumor cells has been evaluated as a predictor of prognosis and response to cytotoxic treatments. Its immunoexpression was assessed in 63 women diagnosed with invasive ductal carcinoma in a retrospective study. The results showed that high GSH expression was associated with tumors negative for the estrogen receptor (ER) $(\mathrm{P}<0.05)$, and GPX expression was associated with tumors negative for the progesterone receptor (PR) and patient mortality. Focusing on the 37 patients who received adjuvant chemotherapy/radiotherapy (Group I), high expression of GPX was associated with a high rate of patient mortality $(\mathrm{P}<0.05)$. The 19 patients who received only adjuvant chemotherapy (Group II) showed high expression of GSH in relation to metastasis $(\mathrm{P}<0.05)$. In addition, high levels of GPX expression were significantly associated with a shorter overall survival $(\mathrm{P}<0.05)$. To confirm this, the expression of precursor genes of GSH [glutamate cysteine ligase (GCLC) and glutathione synthetase (GSS)] and the GPX gene was analyzed using quantitative PCR in cultured neoplastic mammary cells treated with doxorubicin. Doxorubicin treatment was able to eliminate tumor cells without alterations in the gene expression of GSS, but led to underexpression of the GCLC and GPX genes. Our results suggest that high levels
\end{abstract}

Correspondence to: Dr Debora Ap. Pires de Campos Zuccari, Laboratory of Molecular Research in Cancer (LIMC), Department of Molecular Biology, Faculty of Medicine of Sao Jose do Rio Preto (FAMERP), Brigadeiro Faria Lima 5416, 15090-000 São José do Rio Preto, SP, Brazil

E-mail: debora.zuccari@famerp.br

Key words: glutathione, immunohistochemistry, real-time PCR, chemotherapy, prognosis of GPX may be related to the development of resistance to chemotherapy in these tumors, response to treatment and the clinical course of the breast cancer patients.

\section{Introduction}

Breast cancer is the second most common type of cancer worldwide and the most common in women $(1,2)$. In Brazil, it is estimated that 52,650 new cases of this tumor emerged in 2012 (2), whereas in the USA and western Europe, the estimate is for 500,000 new cases/year (3). Despite the high incidence, early diagnosis and introduction of more effective treatments make it possible to reduce mortality and improve the quality of life of patients with this disease (4).

Every prognostic marker employed for determining global patient survival is capable of generating important information related to the clinical behavior of mammary gland tumors. However, in most cases, they neither predict disease progression nor the response to chemotherapy $(5,6)$. According to vant't Veer et al (5), women with breast cancer at the same disease stage can have completely different responses to the same treatment.

Systemic treatment of breast cancer includes the use of cytotoxic, hormonal and immunotherapeutic agents. In general, these treatments are active at the beginning of therapy in $90 \%$ of primary breast cancers and 50\% of metastases; however, after a variable period, the disease tends to progress $(1,7)$.

Better predictive and prognostics markers are needed in clinical practice (8), since studies of clinical and molecular characteristics of tumors allow therapeutic strategies to be designed more efficiently and with less toxicity $(1,4,9)$. In this context, the expression of antioxidant proteins in tumor cells has been assessed as a predictive and prognosis factor of the response to cytotoxic treatments (10-12).

Glutathione (GSH) is a tripeptide comprising of glycine, cysteine and glutamic acid residues (13). Its synthesis requires the participation of two enzymes consecutively. First glutamate cysteine ligase enzyme (GCLC) conjugates glutamic acid and cysteine, producing $\gamma$-glutamyl cysteine. This compound with 
Table I. Specifications and manufacturers of the antibodies used for the study.

\begin{tabular}{llcll}
\hline Antibody & Clonality & Dilution & Buffer & Company \\
\hline Primary antibody anti-ER & Monoclonal & $1: 100$ & Tris EDTA pH 9.0 & Dako \\
Primary antibody anti-PR & Monoclonal & $1: 100$ & Tris EDTA pH 9.0 & Biocare Medical \\
Primary antibody anti-HER-2/neu & Polyclonal & $1: 200$ & Tris EDTA pH 9.0 & Dako \\
Primary antibody anti-p53 & Monoclonal & $1: 500$ & Tris EDTA pH 9.0 & Zymed \\
Primary antibody anti-Ki-67 & Monoclonal & $1: 100$ & EDTA pH 8.0 & Spring \\
Primary antibody anti-GSH & Monoclonal & $1: 100$ & Citrate pH 6.0 & Millipore \\
Primary antibody anti-GPX & Polyclonal & $1: 1,200$ & Citrate pH 6.0 & Abcam \\
\hline
\end{tabular}

ER, estrogen receptor; PR, progesterone receptor; HER-2/neu, human epidermal growth factor receptor-2; GSH, glutathione; GPX, glutathione peroxidase.

its sulfhydryl group (SH) is responsible for the antioxidant activity of GSH. The second step is the binding of $\gamma$-glutamyl cysteine to glycine catalyzed by glutathione synthetase (GSS), producing the tripeptide $\gamma$-glutamyl cysteine glycine, known as $\operatorname{GSH}(14,15)$.

Glutathione peroxidase (GPX) contains selenium at a catalytic site and uses GSH as an electron donor for the reduction of $\mathrm{H}_{2} \mathrm{O}_{2}$ to $\mathrm{H}_{2} \mathrm{O}$, converting itself to its oxidized form, glutathione disulfide (GSSG) $(16,17)$. GSH is considered one of the most important agents of the antioxidant defense system of the cell. Because it is conjugated to GPX, GSH plays a role in the removal of xenobiotic and carcinogenic agents (18).

High levels of GSH and/or GPX increase the antioxidant capacity, as observed in many tumor cells. Although the mechanism and the consequences of these changes are not well characterized (17), recent research has demonstrated that an increase in antioxidants in neoplastic mammary tissue provides certain advantages to these cells when compared to healthy tissue. The presence of these enzymes in neoplastic cells may represent a low-grade response to treatments that cause oxidative damage, such as radiotherapy and various chemotherapeutics $(19,20)$.

These previous findings show the importance of GSH and GPX expression in tumor cells, making them potential predictive and prognostic markers for breast cancer. Thus, the aim of this study was to determine the prognostic and predictive values of GSH and GPX expression and their relationship to several clinicopathological parameters, patient overall survival, and response to breast cancer treatment.

\section{Materials and methods}

\section{Immunohistochemical study}

Sample characterization. In a retrospective study, tumor fragments were selected from 63 women aged 30 to 99 years (mean 58 years) attending the Obstetrics and Gynecology service, Hospital de Base, Faculty of Medicine of São José do Rio Preto from 2000 to 2005. The clinicopathological parameters of the patients were obtained from the service medical records.

Patients with no other malignancy who were subjected to mastectomy/quandrantectomy but not to neoadjuvant chemotherapy/radiotherapy were included in the study. All the patients had been diagnosed with invasive ductal carcinoma.
A panel of classic prognostic markers were evaluated: estrogen receptor (ER), progesterone receptor (PR), human epidermal growth factor receptor-2 (HER-2/neu), p53 tumor-suppressor gene and the cell proliferation marker, Ki-67. Furthermore, the patients were divided in to 4 subgroups according to the immunohistochemistry of the following markers: luminal A $\left(\mathrm{ER}^{+} \mathrm{PR}{ }^{+} \mathrm{HER}-2 / \mathrm{neu}^{-}\right)$, luminal B $\left(\mathrm{ER}^{+} \mathrm{PR}^{+} \mathrm{HER}-2 / \mathrm{neu}^{+}\right)$, HER-2/neu ${ }^{+}$, and triple-negative (ER-PR-HER-2/neu').

The parameters for histopathological evaluation were those recommended by the International Union Against Cancer (UICC) TNM classification of 1989. Among the entire group, 37 patients $(59 \%)$ who had received the same treatment including surgery and adjuvant chemotherapy/radiotherapy [5-fluorouracil/epirubicin/cyclophosphamide (FEC)] were designated as group I; 19 patients (30\%) who had received only adjuvant chemotherapy were designated as group II and 7 patients $(11 \%)$ who had received no treatment after surgery were designated as group III. The patients underwent clinical evaluation every 3-4 months. Local tumor recurrence and metastasis in such cases were carefully monitored, as well as the date and cause of death in order to record the survival time of each patient.

Patient follow-up ranged from 120 to 2,704 days, with a median of 1,473 days. For analysis of survival curves, the patients were divided into higher and lower enzyme expression groups using a cut-off value established by the receiver operating characteristic curve (ROC). Only patients who died of tumor disease were included in the final analysis. Patients with an incomplete follow-up were excluded. The study was approved by the Research Ethics Committee of the Faculty of Medicine of São José do Rio Preto (protocol no. 25372009).

Immunohistochemical technique. For administration of the technique, blocks of paraffin-embedded tumor fragments were cut to provide $3-\mu \mathrm{m}$ sections. The sections were prepared on silanized slides and subsequently deparaffinized, rehydrated through graded alcohol and incubated with 3\% hydrogen peroxidase for $30 \mathrm{~min}$ to block endogenous peroxidase activity. Antigen retrieval was carried out in a Pan Steam (ARNO, São Paulo, Brazil) at $95^{\circ} \mathrm{C}$ with buffer for $35 \mathrm{~min}$ for each specific antibody (Table I). After cooling, the slides were covered with bovine serum albumin (BSA) solution for $30 \mathrm{~min}$ and incubated at $4^{\circ} \mathrm{C}$ overnight with the antibodies described in Table I. 
Subsequently they were washed with phosphate-buffered saline (PBS) for 15 min and incubated with the Easy Path kit (Erviegas, São Paulo, Brazil), which consisted of the secondary antibody biotinylated anti-mouse, rabbit, and goat immunoglobulins for $1 \mathrm{~h}$ and the streptavidin-peroxidase complex for $30 \mathrm{~min}$, followed by washing with PBS for $15 \mathrm{~min}$. We applied $0.5 \%$ 3,3'-diaminobenzidine tetrahydrochloride (DAB; Signet Laboratories, Dedham, MA, USA) to the slides for 2-5 min at $20-22^{\circ} \mathrm{C}$. The slides were counterstained with Harris's hematoxylin for $40 \mathrm{sec}$. Negative controls were obtained by omitting the primary antibody, and liver or prostate tissue served as an internal positive control in every assay.

Evaluation of immunohistochemical staining. To assess the immunoexpression of GSH and GPX, multiple fields were examined on each slide, particularly demarcated areas with distinct brown staining. The slides were photographed and the enzymes were quantified by AxioVision software and by observation through a $\mathrm{x} 40$ lens of a Zeiss Axioskop2 microscope.

For each sample, three regions of tumor tissue were selected and 20 spots of the tumor cells were marked within each region, thereby analyzing 60 different spots of every sample to average the relative intensity of immunoreactivity. The values were obtained as arbitrary units (au), and the mean optical density (MOD) indicated the specific staining intensity in the immunoreactive areas.

The staining of HER-2/neu was considered by counting the number of positively stained cells in the membrane and was expressed as a percentage of the total tumor cells. According to ASCO/CAP guidelines (21) the following categories were defined: 0 , no immunostaining; $1+$, weak or incomplete staining of the membrane in any proportion of tumor cells; $2+$, complete membrane staining or weak staining in $10 \%$ of the tumor cells stained; $3+$, uniform and intense staining of the membrane in more than $30 \%$ of tumor cells. Tumors scored with 0 or $1+$ were considered negative and those with scores $2+$ or $3+$ were considered positive. Tumors were categorized into two groups in relation to cellular proliferation according to the staining of $\mathrm{Ki}-67$ based on the count of the number of positively stained cells and expressed as a percentage of the total: 0 or 1 , no cellular proliferation; 2 or 3 , the presence of cellular proliferation. The same parameter was used in the classification of the ER, PR and p53 tumor-suppressor gene: 0 or 1 , no staining; 2, 3 or 4 , presence of staining.

Statistical analysis. The patients were separated into groups according to the clinicopathological variables. The averages of the densitometric analysis referring to the densitometry results and the quantification of the different breast tumor groups were compared by Student's t-test or ANOVA, followed by the Bonferroni test. The values are expressed as means \pm SEM.

The cut-off for the risk of death was determined by ROC. Survival curves were plotted by the Kaplan-Meier method, and the differences between the curves were evaluated by a log-rank test and hazard function. Multivariate logistic regression was performed to evaluate the factors that influenced death. For all tests, $\mathrm{P}<0.05$ was considered to indicate a statistically significant result. All analyses were performed using GraphPad Prism 4 and StatsDirect software.

\section{Molecular study}

Sample characterization. Twelve core biopsies or tumor fragments $>2 \mathrm{~cm}$ were collected by surgery from the breast cancer patients who were diagnosed with ductal carcinoma, who had not undergone chemotherapy and/or radiation therapy prior to the point of collection. The tumor fragments were washed in PBS containing $1 \%$ penicillin/streptomycin, cut into microfragments with a scalpel and incubated at $37^{\circ} \mathrm{C}$ in $5 \% \mathrm{CO}_{2}$ with RPMI-1640 supplemented with $20 \%$ BSA, $1 \%$ penicillin/ streptomycin and $1 \%$ L-glutamine. The cells were cultivated until they reached $80 \%$ confluence and were subjected to immunocytochemistry using the primary antibodies anticytokeratin, anti-vimentin and anti-calponin to confirm epithelial origin.

Treatment of the cells in vitro. Cells were divided into two groups: control (no treatment), and cells treated with $0.2 \mathrm{mg}$ routine chemotherapy (doxorubicin) for $24 \mathrm{~h}$. At the end of the treatment, cell viability was verified by cell counting in a Neubauer chamber (LaborOptik, Bad Homburg, Hessen, Germany) with trypan blue dye $(0.4 \%)$.

Quantitative PCR. Total RNA was extracted from the cell culture with TRIzol (Invitrogen Life Technologies, São Paulo, Brazil) as recommended by the laboratory and the total RNA from each sample was reverse transcribed to complementary DNA (cDNA) using a High Capacity cDNA kit (Applied Biosystems, Foster City, CA, USA).

Quantitative real-time polymerase chain reactions were performed in triplicate using StepOnePlus ${ }^{\mathrm{TM}}$ System (Applied Biosystems). Briefly, the reactions were performed in a $20 \mu \mathrm{l}$ volume with $10 \mu \mathrm{l}$ of Power SYBR ${ }^{\circledR}$-Green PCR Master Mix (Applied Biosystems), $250 \mathrm{nM}$ of each primer, and $10 \mathrm{ng}$ of cDNA. PCR conditions consisted of $50^{\circ} \mathrm{C}$ for $2 \mathrm{~min}, 95^{\circ} \mathrm{C}$ for $10 \mathrm{~min}$, followed by 35 cycles of $95^{\circ} \mathrm{C}$ for $15 \mathrm{sec}$ and $60^{\circ} \mathrm{C}$ for $1 \mathrm{~min}$. Following PCR, dissociation curve analysis was performed to confirm the desired single gene product: one cycle of $95^{\circ} \mathrm{C}$ for $15 \mathrm{sec}, 60^{\circ} \mathrm{C}$ for $1 \mathrm{~min}$, and $95^{\circ} \mathrm{C}$ for $15 \mathrm{sec}$ was carried out.

Each transcript level was normalized by division with the expression values of HPRT1 used as an internal control. Gene expression stability was analyzed by geNorm software. The transcript level was calculated using the $2^{-\mathrm{Ct}}$ method (22). The $\mathrm{Ct}$ was the difference between the threshold cycles of the target and the internal control and $\mathrm{Ct}$ was the difference between the average $\mathrm{Ct}$ of the sample and the average $\mathrm{Ct}$ of the calibrator sample. The fold difference (relative abundance) was calculated using the $2^{-\Delta \Delta \mathrm{CT}}$ formula and plotted as mean $\pm \mathrm{SD}$ of the triplicate reactions. At least 3-fold differences were considered significant.

A negative control was included in each reaction, and one sample was chosen for reaction calibration. Experiments were repeated when the coefficient of variation was higher than $5 \%$. After each reaction, the products were analyzed on $2 \%$ agarose gel stained with ethidium bromide.

The gene was searched, selected in PubMed (http://www. ncbi.nlm.nih.gov/entrez), and synthesized from human messenger RNA already sequenced and confirmed. Its design was made using the program PRIMER 3 (http://frodo.wi.mit. edu/cgi-bin/primer3/primer3_www.Cgi). The HPRT1 gene 

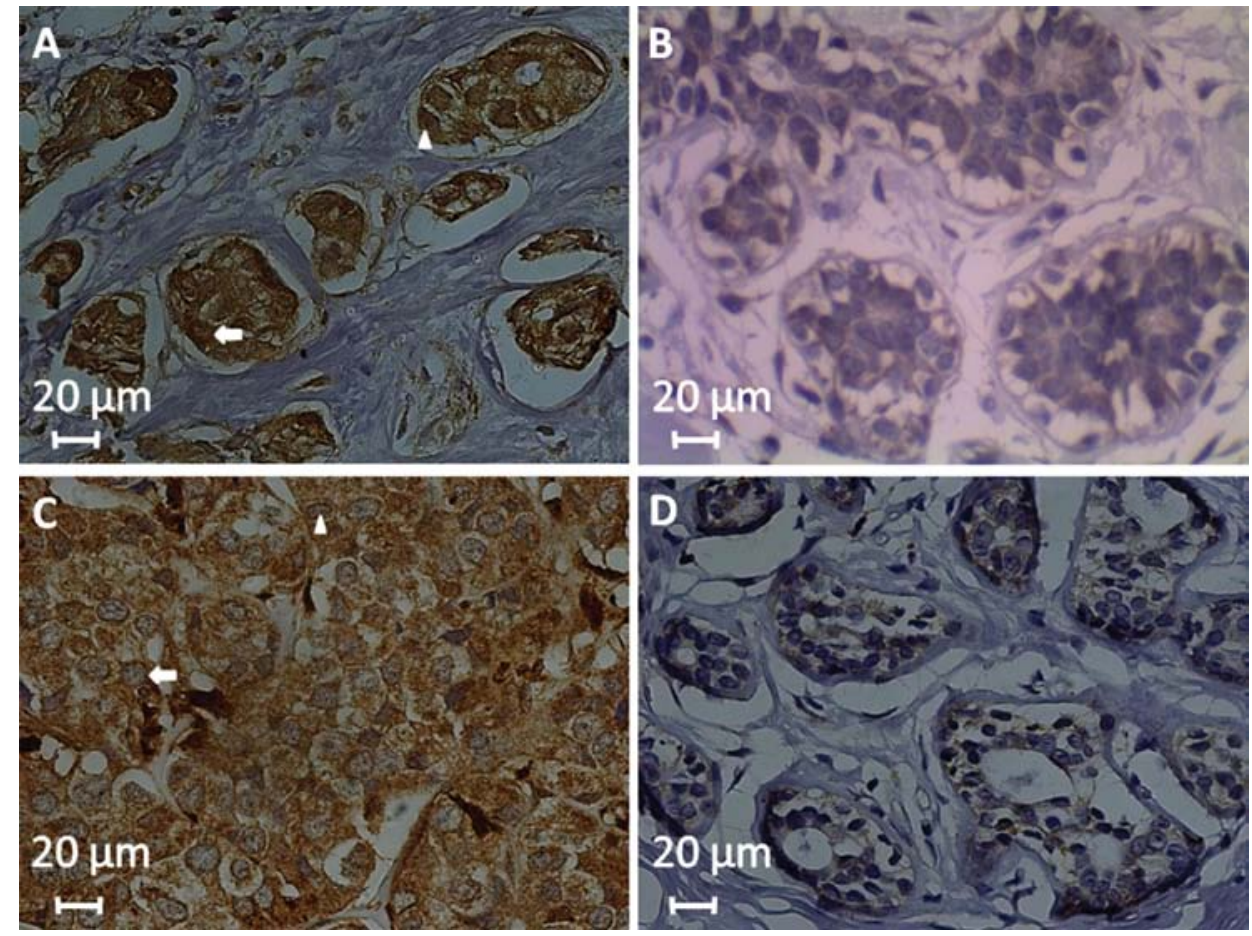

Figure 1. Images of immunohistochemical staining for GSH and GPX (original magnification x400). (A) Immunostaining for GSH in breast cancer Immunostaining was evident in the cytoplasm (arrow) and nucleus (arrowhead) of neoplastic cells. (B) Immunostaining for GSH in normal breast tissue of patients, with weak immunoreactivity in the cytoplasm of cells. (C) Immunostaining for GPX in breast cancer. Immunostaining was evident in the cytoplasm (arrow) and was focally present in the nucleus (arrowhead) of neoplastic cells. (D) Immunostaining for GPX in normal breast tissue, with weak immunoreactivity in the cytoplasm of cells.

was used as an endogenous control. Primers used for amplification include: GSS foward, 5'-TGCTAAAGCCCCAGAGAG AG-3' and reverse, 5'-AGCAGGCAATTCTCAAAAGG-3'; GCLC foward, 5'-GCACAACGTTCTCAAGTG-3' and reverse, 5'-TGGTTTGGGTTTGTCCTTTC-3'; GPX foward, 5'-ATGGCGCAATTGTCCAAG-3' and reverse, 5'-CTGGCC TCCCCTTACAGTG-3'; HPRT1 foward, 5'-TTATAGTCAAG GGCATATCC-3' and reverse, 5'-AGCTTGCTGGTGAAA AGGAC-3'.

The genes were classified as underexpressed (samples with less than $-1 \log 3$ measurement) and overexpressed (samples with quantification greater than $1 \log 3$ ).

\section{Results}

All tumors were histological grade II invasive ductal carcinoma, with a preponderance of tumors of clinical stage II (76.2\%), in agreement with the TNM (tumor, node and metastasis) classification.

Immunohistochemical procedure. Immunostaining of GSH and GPX was evident in the cytoplasm and focally in the nuclei of the neoplastic cells, whereas the stroma showed no reactivity (Fig. 1).

Regarding the classical markers, GSH expression was correlated with tumor ER-positivity, and GPX correlated with tumor PR-negativity $(\mathrm{P}=0.03)$ (Table II). Only 13 (20.6\%) of the patients had tumors with luminal expression A (ER ${ }^{+} \mathrm{PR}^{+} \mathrm{HER}-2 / \mathrm{neu}^{-}$), whereas $22(35 \%)$ of the patients had tumors with luminal expression $\mathrm{B}\left(\mathrm{ER}^{+} \mathrm{PR}^{+} \mathrm{HER}-2 / \mathrm{neu}^{+}\right)$;
$41(65 \%)$ patients were HER-2/neu ${ }^{+}$independently of the hormone receptors, and $9(14.2 \%)$ patients had a triple-negative (ER- PR-HER-2/neu') phenotype. Nevertheless, there was no correlation between GSH or GPX expression and the different clinical groups $(\mathrm{P}>0.05)$.

Immunohistochemical expression of GSH and GPX was assessed in relation to the clinical course of the patients, taking into account local recurrence, metastasis and/or rate of mortality (Table II). High expression of GPX was significantly correlated with a high rate of patient mortality $(\mathrm{P}=0.03)$ (Table III). Group I showed higher GPX expression in patients that succumbed to disease $(\mathrm{P}=0.02)$ and Group II showed higher GSH expression in patients with metastasis $(\mathrm{P}=0.03)$ (Table III).

ROC was calculated to explore the performance, and the threshold values for GSH and GPX expression were used to predict the risk of mortality in breast cancer patients. The ROC graph indicated calculations for sensitivity/specificity of the patients. Thus, the best cut-off value for GSH to discriminate high risk of death in all patients was MOD $=170$ au (sensitivity $=30 \%$ and specificity $=88 \%$ ). For GPX the best cut-off in the total population was: $\mathrm{MOD}=200 \mathrm{au}$ (sensitivity $=60 \%$ and specificity $=67 \%$ ).

Multivariate logistic regression showed that clinical stages III or IV and metastasis were associated with an increased risk of mortality in the breast cancer patients $(\mathrm{P}<0.05)$ (Table IV). In addition, in patients $>50$ years of age, high levels of cell proliferation (Ki-67 positivity), local recurrence and higher GPX expression showed a significant trend towards an increased risk of mortality $(\mathrm{P}=0.05-0.06)$ (Table IV). 
Table II. Mean expression of GSH and GPX and its correlation with clinicopathological characteristics of the breast cancer patients

\begin{tabular}{|c|c|c|c|}
\hline $\begin{array}{l}\text { Clinicopathological } \\
\text { factors }\end{array}$ & $\begin{array}{c}\text { No. of patients } \\
\mathrm{n}(\%)\end{array}$ & MOD of GSH & MOD of GPX \\
\hline \multicolumn{4}{|l|}{ Patient age (years) } \\
\hline$\geq 50$ & $16(25.4)$ & $187.8 \pm 3.517$ & $192.6 \pm 2.234$ \\
\hline$<50$ & $47(75.6)$ & $184.3 \pm 3.253$ & $194.1 \pm 4.240$ \\
\hline P-value & & 0.54 & 0.74 \\
\hline \multicolumn{4}{|l|}{ Smoker } \\
\hline Yes & $11(17.5)$ & $188.0 \pm 5.177$ & $196.7 \pm 5.951$ \\
\hline No & $52(82.5)$ & $184.3 \pm 2.887$ & $192.2 \pm 2.041$ \\
\hline P-value & & 0.58 & 0.38 \\
\hline \multicolumn{4}{|l|}{ Hormone therapy } \\
\hline Yes & $11(17.5)$ & $179.7 \pm 4.918$ & $195.9 \pm 4.863$ \\
\hline No & $52(82.5)$ & $186.3 \pm 2.842$ & $192.3 \pm 2.164$ \\
\hline P-value & & 0.32 & 0.49 \\
\hline \multicolumn{4}{|c|}{ Lymph node involvement } \\
\hline Positive & $13(20.6)$ & $186.2 \pm 4.546$ & $193.7 \pm 4.464$ \\
\hline Negative & $50(79.4)$ & $184.7 \pm 2.992$ & $192.5 \pm 2.249$ \\
\hline P-value & & 0.81 & 0.80 \\
\hline \multicolumn{4}{|l|}{ Histological grade } \\
\hline $\mathrm{I}$ & $3(4.7)$ & $175.5 \pm 21.50$ & $191.0 \pm 5.000$ \\
\hline II & $50(79.4)$ & $184.0 \pm 2.837$ & $192.2 \pm 2.301$ \\
\hline III & $10(15.9)$ & $190.9 \pm 5.360$ & $194.9 \pm 3.650$ \\
\hline P-value & & 0.30 & 0.51 \\
\hline \multicolumn{4}{|l|}{ Clinical stage } \\
\hline $\mathrm{I}$ & 4 (6.3) & $175.3 \pm 8.686$ & $204.0 \pm 13.320$ \\
\hline II & $48(76.2)$ & $185.4 \pm 3.112$ & $192.6 \pm 2.207$ \\
\hline III & $9(14.3)$ & $185.4 \pm 5.373$ & $188.9 \pm 5.832$ \\
\hline IV & $2(3.2)$ & $195.5 \pm 0.500$ & $199.5 \pm 0.500$ \\
\hline P-value & & 0.75 & 0.51 \\
\hline \multicolumn{4}{|c|}{ Median tumor diameter $(\mathrm{cm})$} \\
\hline$>3 \mathrm{~cm}$ & $13(20.6)$ & $186.9 \pm 4.190$ & $196.8 \pm 3.211$ \\
\hline$\leq 3 \mathrm{~cm}$ & $50(79.4)$ & $184.5 \pm 3.022$ & $192.0 \pm 2.329$ \\
\hline P-value & & 0.69 & 0.32 \\
\hline \multicolumn{4}{|l|}{ Estrogen receptor } \\
\hline Positive & $46(73)$ & $188.1 \pm 2.089$ & $191.4 \pm 2.484$ \\
\hline Negative & $17(27)$ & $176.4 \pm 7.285$ & $197.2 \pm 2.671$ \\
\hline P-value & & $0.03^{\mathrm{a}}$ & 0.19 \\
\hline \multicolumn{4}{|l|}{ Progesterone receptor } \\
\hline Positive & $37(58.7)$ & $188.3 \pm 2.330$ & $189.4 \pm 2.870$ \\
\hline Negative & $26(41.3)$ & $1802 \pm 5.106$ & $198.0 \pm 2.160$ \\
\hline P-value & & 0.11 & $0.03^{\mathrm{a}}$ \\
\hline \multicolumn{4}{|l|}{ HER-2/neu } \\
\hline Positive & $41(65)$ & $188.1 \pm 2.199$ & $193.1 \pm 2.447$ \\
\hline Negative & $22(35)$ & $178.8 \pm 6.180$ & $192.6 \pm 3.389$ \\
\hline $\mathrm{P}$-value & & 0.08 & 0.90 \\
\hline \multicolumn{4}{|l|}{ p53 } \\
\hline Positive & $44(69.8)$ & $184.4 \pm 3.353$ & $194.8 \pm 2.322$ \\
\hline Negative & $19(30.2)$ & $186.4 \pm 3.747$ & $188.7 \pm 3.606$ \\
\hline P-value & & 0.73 & 0.16 \\
\hline \multicolumn{4}{|c|}{ Ki-67 cell proliferation index } \\
\hline High & $30(47.6)$ & $185.3 \pm 4.526$ & $194.2 \pm 2.878$ \\
\hline Low & $33(52.4)$ & $183.9 \pm 2.680$ & $191.8 \pm 2.724$ \\
\hline P-value & & 0.78 & 0.54 \\
\hline
\end{tabular}

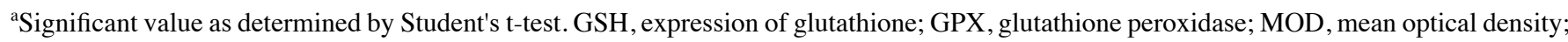
HER-2/neu, human epidermal growth factor receptor-2. 
Table III. Association of GSH and GPX expression and treatment and clinical outcome of the breast cancer patients.

\begin{tabular}{|c|c|c|c|c|}
\hline Group & Clinical outcome & $\begin{array}{c}\text { No. of patients } \\
\mathrm{n}(\%)\end{array}$ & MOD of GSH & MOD of GPX \\
\hline \multirow[t]{12}{*}{ Total Group } & Local recurrence & & & \\
\hline & Yes & $6 \quad(9.5)$ & $179.7 \pm 3.412$ & $196.3 \pm 9.315$ \\
\hline & No & $57(90.5)$ & $185.5 \pm 2.778$ & $192.3 \pm 2.004$ \\
\hline & P-value & & 0.50 & 0.56 \\
\hline & Metastasis & & & \\
\hline & Yes & $23(36.5)$ & $186.8 \pm 3.030$ & $196.5 \pm 3.379$ \\
\hline & No & $40(63.5)$ & $183.9 \pm 3.617$ & $190.9 \pm 2.389$ \\
\hline & P-value & & 0.59 & 0.17 \\
\hline & Death due to disease & & & \\
\hline & Yes & $20(32)$ & $183.5 \pm 3.549$ & $199.1 \pm 2.867$ \\
\hline & No & $43(68)$ & $185.7 \pm 3.354$ & $190.1 \pm 2.459$ \\
\hline & P-value & & 0.68 & $0.03^{\mathrm{a}}$ \\
\hline \multirow[t]{12}{*}{ Group I } & Local recurrence & & & \\
\hline & Yes & $5(13.5)$ & $180.4 \pm 4.082$ & $203.2 \pm 6.111$ \\
\hline & No & $32(86.5)$ & $184.1 \pm 4.326$ & $192.3 \pm 2.705$ \\
\hline & P-value & & 0.74 & 0.14 \\
\hline & Metastasis & & & \\
\hline & Yes & $14(38)$ & $181.6 \pm 4.223$ & $196.3 \pm 4.908$ \\
\hline & No & $23(62)$ & $184.8 \pm 5.556$ & $192.3 \pm 2.808$ \\
\hline & P-value & & 0.68 & 0.44 \\
\hline & Death due to disease & & & \\
\hline & Yes & $13(35)$ & $179.3 \pm 4.033$ & $201.6 \pm 3.362$ \\
\hline & No & $24(65)$ & $185.9 \pm 5.393$ & $189.5 \pm 3.163$ \\
\hline & P-value & & 0.41 & $0.02^{\mathrm{a}}$ \\
\hline \multirow[t]{12}{*}{ Group II } & Local recurrence & & & \\
\hline & Yes & $1 \quad(5)$ & $176.0 \pm 0.000$ & $158.0 \pm 0.000$ \\
\hline & No & $18(95)$ & $185.1 \pm 4.195$ & $193.1 \pm 4.009$ \\
\hline & P-value & & - & - \\
\hline & Metastasis & & & \\
\hline & Yes & $6(31.5)$ & $196.8 \pm 3.311$ & $200.2 \pm 5.382$ \\
\hline & No & $13(68.5)$ & $179.9 \pm 4.954$ & $187.2 \pm 5.384$ \\
\hline & P-value & & $0.03^{\mathrm{a}}$ & 0.15 \\
\hline & Death due to disease & & & \\
\hline & Yes & $5(26)$ & $189.2 \pm 8.789$ & $190.0 \pm 5.030$ \\
\hline & No & $14(74)$ & $183.0 \pm 4.555$ & $191.7 \pm 5.532$ \\
\hline & P-value & & 0.51 & 0.86 \\
\hline \multirow[t]{12}{*}{ Group III } & Local recurrence & & & \\
\hline & Yes & $0 \quad(0)$ & - & - \\
\hline & No & $7(100)$ & $193.3 \pm 2.168$ & $195.3 \pm 4.412$ \\
\hline & P-value & & - & - \\
\hline & Metastasis & & & \\
\hline & Yes & $3(43)$ & $191.0 \pm 2.309$ & $195.0 \pm 11.060$ \\
\hline & No & $4(57)$ & $195.0 \pm 3.391$ & $195.5 \pm 2.630$ \\
\hline & P-value & & 0.41 & 0.96 \\
\hline & Death due to disease & & & \\
\hline & Yes & $2(28.5)$ & $196.0 \pm 1.000$ & $205.0 \pm 12.00$ \\
\hline & No & $5(71.5)$ & $192.2 \pm 2.956$ & $191.4 \pm 3.641$ \\
\hline & P-value & & 0.47 & 0.18 \\
\hline
\end{tabular}


Table IV. Results of the multivariate logistic regression analysis.

\begin{tabular}{lccc}
\hline Variables & OR & 95\% CI & P-value \\
\hline Age $\geq 50$ years & 918.55 & $0.99-851,872.18$ & $0.05^{\mathrm{a}}$ \\
Smoker & 2.30 & $0.00-6,851.12$ & 0.83 \\
Large tumor size $(>3 \mathrm{~cm})$ & 1.32 & $0.05-33.00$ & 0.86 \\
Lymph node involvement & 31.62 & $0.39-2517.38$ & 0.12 \\
Staging III or IV & 460.42 & $1.33-15,8371.26$ & $0.03^{\mathrm{b}}$ \\
Histological grade III & 0.01 & $0.00-86.94$ & 0.32 \\
ER positivity & 14.97 & $0.42-525.45$ & 0.13 \\
PR positivity & 0.007 & $0.00-1.73$ & 0.07 \\
HER-2/neu negativity & 11.26 & $0.33-378.73$ & 0.17 \\
Cell proliferation (Ki-67 positivity) & 66.57 & $0.75-5,905.44$ & $0.06^{\mathrm{a}}$ \\
p53 positivity & 0.018 & $0.00-1.56$ & 0.07 \\
Chemotherapy & 15.22 & $0.05-4,337.16$ & 0.34 \\
Radiotherapy & 0.12 & $0.00-5.31$ & 0.27 \\
Metastasis & $1,397.97$ & $7.90-247,365.34$ & $0.006^{\mathrm{b}}$ \\
Local recurrence & $57,817.26$ & $0.98-3,390,813,161.68$ & $0.05^{\mathrm{a}}$ \\
High GSH expression & 0.16 & $0.001-14.42$ & 0.43 \\
High GPX expression & 117.26 & $0.68-19,969.60$ & $0.06^{\mathrm{a}}$ \\
\hline
\end{tabular}

${ }^{a}$ Trend toward significance; ${ }^{b}$ statistically significant value. OR, odds ratio; CI, confidence interval; ER, estrogen receptor; PR, progesterone receptor; HER-2/neu, human epidermal growth factor receptor-2; GSH, glutathione; GPX, glutathione peroxidase.

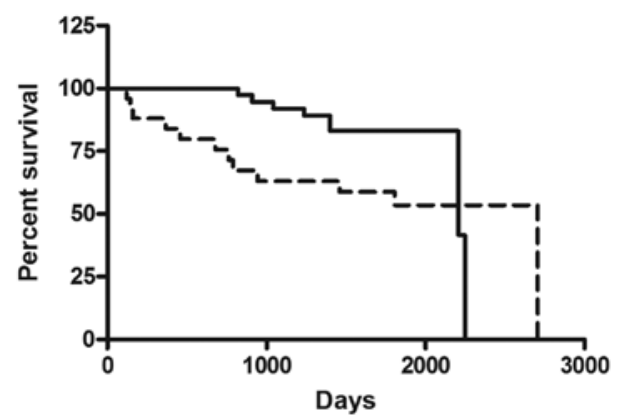

Figure 2. Overall survival of the patients with high (dotted line) and low (continuous line) GPX expression. (Cut-off selected was MOD $=200 \mathrm{au}$; $\mathrm{P}=0.03$; OR, 2.63; 95\% CI, 1.05-7.01). OR, odds ratio; CI, confidence interval.

Patient follow-up ranged from 144 days ( 0.4 years) to 2,704 days ( 7.4 years) with a median of 1,542 days (4.2 years). For analysis of the survival curves, the patients were divided into higher and lower enzyme expression groups using a cut-off value established from the ROC curve. There was no correlation between GSH expression and overall survival in groups I, II and III ( $\mathrm{P}>0.05)$. High GPX expression was correlated with a lower overall survival rate in the entire group $(\mathrm{P}=0.03)$ (Fig. 2).

Quantitative PCR. Samples collected for the in vitro study were from patients diagnosed with invasive ductal carcinoma; 3 patients with histological grade I (25\%), 6 with grade II (50\%) and 3 with grade III $(25 \%)$. Only one patient had local recurrence and 1 patient died of metastasis. Following cell culture, the epithelial origin was confirmed by immunocytochemistry, and GCLC, GSS and GPX gene expression was evaluated after treatment with doxorubicin.

The GCLC gene, responsible for the first step in the synthesis of $\mathrm{GSH}$, was underexpressed in 7 (58.3\%) of the culture samples following treatment with chemotherapy. This gene was overexpressed in one $(8.3 \%)$ of the samples, and $4(33.3 \%)$ samples failed to reach the minimum level of expression in the $\log 3$ range required to be considered indistinguishable from the controls (Fig. 3). Only in $1(8.3 \%)$ culture sample treated with chemotherapy was the GSS gene overexpressed. Eleven (91.6\%) samples fail to reach the minimum level of expression in the $\log 3$ range required to be considered indistinguishable from the controls (Fig. 4).

The GPX gene was underexpressed in $6(50 \%)$ of the culture samples treated with chemotherapy. Only one $(8.3 \%)$ sample showed overexpression and $5(41.6 \%)$ samples showed no significant difference in expression compared to the control cells (Fig. 5).

\section{Discussion}

Studies concerning the association between immunohistochemical expression of GSH, as well as GPX, the clinicopathological parameters of breast cancer patients are sparse. The majority of previous studies have used biochemical methods to quantify the activity of these proteins, comparing patients with breast cancer and healthy control patients $(19,20,23,24)$.

In this study, tumors considered ER-positive presented higher expression of the GSH protein when compared to those that were ER-negative. In addition, PR-negative tumors presented higher expression of GPX compared to those that were PR-positive. According to Fernandes et al (25), indi- 


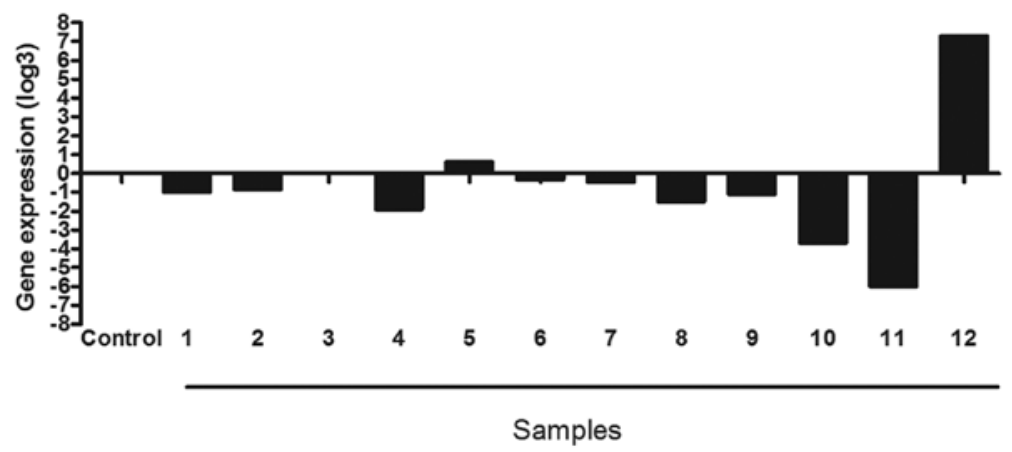

Figure 3. Quantitative gene expression of GCLC in the breast cancer cells. Quantitative gene expression in cells exposed to doxorubicin in relation to the pool of unexposed cells (control). Value of gene expression in $\log 3$.

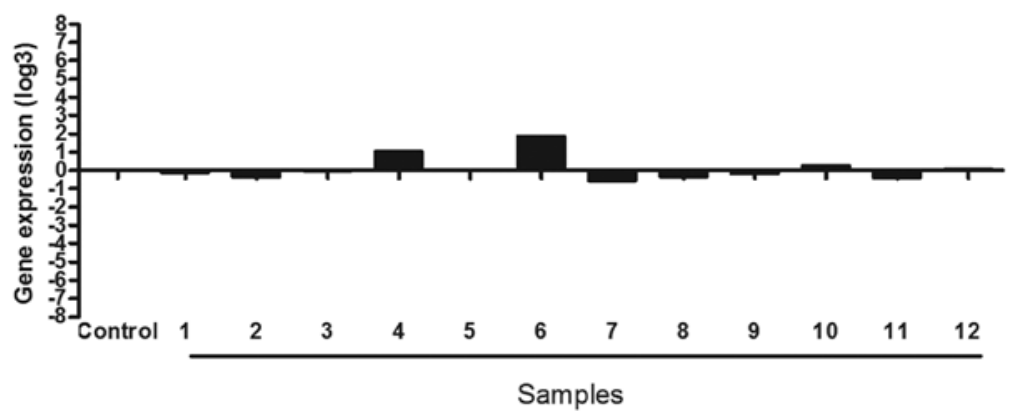

Figure 4. Quantitative gene expression of GSS in the breast cancer cells. Quantitative gene expression in cells exposed to doxorubicin in relation to the pool of unexposed cells (control). Value of gene expression in $\log 3$.

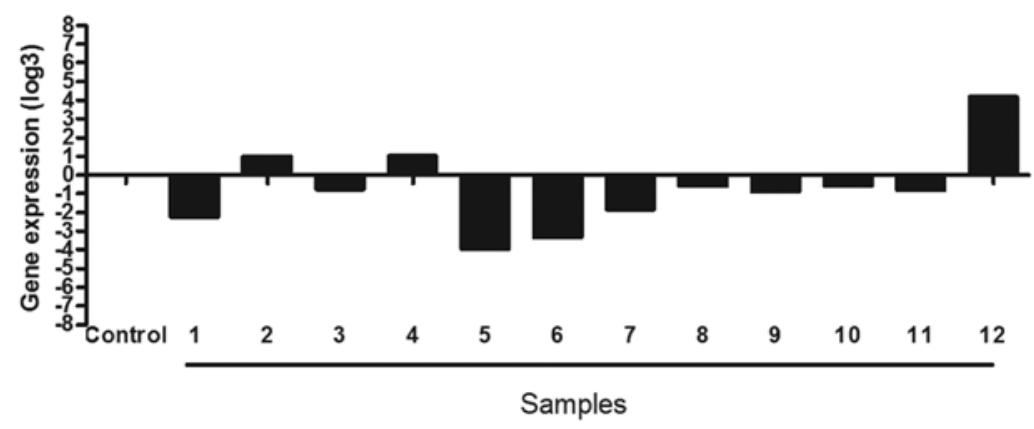

Figure 5. Quantitative gene expression of GPX in the breast cancer cells. Quantitative gene expression in cells exposed to doxorubicin in relation to the pool of unexposed cells (control). Value of gene expression in $\log 3$.

vidual analyses of the hormonal receptors are not conclusive. With the combined evaluation of hormonal receptors and the HER-2/neu protein, mammary carcinomas can be grouped into 4 main subtypes that provide important information related to the degree of malignancy and therapeutic response to certain drugs $(25,26)$. Triple-negative carcinomas are considered more aggressive than the luminal A or B subtypes, or even those overexpressing HER-2/neu. There was no statistical correlation between GSH and GPX expression and these carcinoma subtypes.

The immunohistochemical expression of GSH and GPX was also related to the clinical progression of the breast cancer patients. Patients that received only adjuvant chemotherapy (Group II) and had metastases showed higher GSH expres- sion. Ballatorri et al (17) demonstrated that a high level of GSH increased the antioxidant capacity of neoplastic cells, making them more resistant to chemotherapy. Based on this, high expression of GSH can be characterized as an indicator of low response to chemotherapy in those analyzed patients in this study, and may have contributed to the development of metastasis.

High expression of GPX was associated with a high rate of mortality, upon univaried and multivariate analyses. In addition, patients with lower GPX expression had a lower overall survival time. The association between high GPX expression and mortality remained significant when evaluated only in the patients restricted to the group of 37 women treated with adjuvant chemotherapy and radiotherapy (Group I). The 
correlations found in this study may be explained on the basis of enzymatic reactions catalyzed by GPX. Some chemotherapeutic and radiotherapeutic protocols potentially increase the already existent oxidative stress in neoplastic processes, causing damage to DNA and cell death (27). High levels of GPX are known to correlate with cellular responses to oxidative stress. In this way, cytotoxic treatments can reduce intracellular GPX concentrations, based on the high concentration of GSSG in the environment, or, on the other hand, cytotoxic treatments can induce GPX expression as a cellular response to a high concentration of $\mathrm{H}_{2} \mathrm{O}_{2}(17,20,28,29)$. A high level of GPX helps prevent oxidative damage that would otherwise lead to tumor cell death due to the applied treatments $(18,19)$.

In vitro studies corroborate the participation of GSH and GPX in cellular resistance to treatments. In this study, there was no significant expression of GSS after treatment with doxorubicin, whereas the GCLC and GPX genes were underexpressed in 58.8 and $50 \%$ of the samples, respectively.

Many studies have demonstrated that alterations in expression of genes responsible for the synthesis of GSH or GPX usually occur after in vitro treatment with doxorubicin or similar drugs. It is suggested that a large production of reactive oxygen species (ROS) following treatment with doxorubicin is responsible for the cytotoxicity noted in neoplastic cells, and as a consequence, these cells overexpress genes responsible for the synthesis of antioxidants, such as GSH and GPX, making them more resistant to oxidative damages (30). Ozkan and Fiskin (31) found that the application of epirubicin (analogous to the structure of doxorubicin) in mammary neoplastic cells reduced GSH and GPX activity within $24 \mathrm{~h}$ of in vitro exposure. More unlikely, a study by Ilvsova et al (32) showed that the total GSH concentration in the blood of breast cancer patients increased significantly $24 \mathrm{~h}$ after doxorubicin administration.

Han et al (33), using the MCF-7 breast cancer cell line, found a high sensitivity to doxorubicin when the levels of GSH decreased. Vibet et al (34) using docosahexaenoic acid, known to increase the oxidative mechanism of chemotherapeutics in mammary neoplastic cells when combined with doxorubicin, showed that a high concentration of ROS, due to this treatment, inhibited GPX activity. The same finding was noted in animal models of breast cancer. In this way, Sun et al (35) observed that high $\mathrm{H}_{2} \mathrm{O}_{2}$ concentrations increased the sensivity of tumor cells in vitro and in vivo not only to doxorubicin, but to ionizing radiation. In contrast, Di et al (36) demonstrated that GSH overexpression did not prevent apoptosis in tumor cells after treatment with doxorubicin, suggesting that the cytotoxicity of this drug is not directly correlated with ROS production.

In conclusion, GPX was highly expressed in breast cancer cells of patients with a worse clinical outcome and reduced overall survival who underwent chemotherapy and radiotherapy. Thus, it is suggested that GPX has an important role in the progression of this disease, especially as a possible prognostic marker for these patients. In addition, there was a relationship between application of the chemotherapeutic drug doxorubicin and reduced expression of the GPX gene, making it a candidate marker for predicting therapeutic responses in breast cancer cases, yet this needs to be confirmed in larger studies.

\section{Acknowledgements}

The authors thank the Capes/Coordenação de Aperfeiçoamento de Pessoal de Nível Superior and FAPESP/Fundação de Amparo à Pesquisa do Estado de São Paulo for their financial support. We are also grateful to Dr Dalisio de Santi Neto, Pathologist of the Department of Pathology and Forensic Medicine - FAMERP for the collaboration in this study.

\section{References}

1. Gonzalez-Angulo AM, Moraes-Vasquez F and Hortobagyl GN: Overview of resistance to systemic therapy in patients with breast cancer. Adv Exp Med Biol 608: 1-22, 2007.

2. Instituto Nacional do Câncer (INCA): Estimativas da incidência e mortalidade por câncer no Brasil. Ministério da Saúde Rio de Janeiro. http://www.inca.gov.br/estimativa/2010/index. asp?link=conteudo_view.asp\&ID=5. Accessed Nov. 20, 2011.

3. Gralow J, Ozols RF, Bajorin DF, et al: Clinical cancer advances 2007: major research advances in cancer treatment, prevention, and screening - a report from the American Society of Clinical Oncology. J Clin Oncol 26: 313-325, 2008.

4. Hicks DG and Kulkarni S: Trastuzumab as adjuvant therapy for early breast cancer. Arch Pathol Lab Med 132: 1008-1015, 2008.

5. vant't Veer LJ, Paik S and Hayes DF: Gene expression profiling of breast cancer: a new tumor marker. J Clin Oncol 23: 1631-1635, 2005.

6. Pedersen L, Gunnarsdottir KA, Rasmussen BB, et al: The prognostic influence of multifocality in breast cancer patients. Breast 13: 188-193, 2004.

7. Duffy MJ and Crown J: A personalized approach to cancer treatment: how biomarkers can help. Clin Chem 54: 1770-1779, 2008.

8. Thomas E and Berner G: Prognostic and predictive implications of HER2 status for breast cancer patients. Eur J Oncol Nurs 4: 10-17, 2000.

9. Duffy MJ, O'Donovan N and Crown J: Use of molecular markers for predicting therapy response in cancer patients. Cancer Treat Rev 37: 151-159, 2011.

10. Pastore A, Federici G, Bertini E and Piemonte F: Analysis of glutathione: implication in redox and detoxification. Clin Chem Acta 333: 19-39, 2003.

11. Townsend DM and Tew KD: The role of glutathione-S-transferase in anti-cancer drug resistance. Oncogene 22: 7369-7375, 2003.

12. Jardim BV, Moschetta MG, Gelaleti GB, et al: Glutathione transferase pi (GSTpi) expression in breast cancer: An immunohistochemical and molecular study. Acta Histochem 114: 510-517, 2012.

13. Huber PC, Almeida WP and Fatima A: Glutationa e enzimas relacionadas: papel biológico e importância em processos patológicos. Quím Nova 31: 1170-1179, 2008.

14. Carnicer MJ, Bernardini S, Bellincampi L, et al: Role of $\gamma$-glutamyl cysteine synthetase $(\gamma$-GCS) gene expression as marker of drug sensitivity in acute myeloid leukemias. Clin Chem Acta 365: 342-345, 2006.

15. Uchida M, Sugaya M, Kanamaru T and Hisatomi H: Alternative RNA splicing in expression of the glutathione synthetase gene in human cells. Mol Biol Rep 37: 2105-2109, 2010.

16. Valko M, Leibfritz D, Moncol J, et al: Free radicals and antioxidants in normal physiological functions and human disease. Int J Biochem Cell Biol 39: 44-84, 2007.

17. Ballatori N, Krance SM, Notenboom S, et al: Glutathione dysregulation and the etiology and progression of human diseases. Biol Chem 390: 191-214, 2009

18. Kumaraguruparan R, Balachandran C, Manohar BM and Nagini S: Altered oxidant-antioxidant profile in canine mammary tumours. Vet Res Commun 29: 287-296, 2005.

19. Rajneesh CP, Manimaran A, Sasikala KR and Adaikappan P: Lipid peroxidation and antioxidant status in patients with breast cancer. Singapore Med J 49: 640-643, 2008.

20. Kasapović J, Pejić S, Stojiljković V, et al: Antioxidant status and lipid peroxidation in the blood of breast cancer patients of different ages after chemotherapy with 5-fluorouracil, doxorubicin and cyclophosphamide. Clin Biochem 43: 1287-1293, 2010 . 
21. Hammond ME, Hayes DF, Dowsett M, et al: American Society of Clinical Oncology/College of American Pathologists guideline recommendations for immunohistochemical testing of estrogen and progesterone receptors in breast cancer. J Clin Oncol 28: 2784-2795, 2010.

22. Livak KJ and Schmittgen TD: Analysis of relative gene expression data using real-time quantitative PCR and the $2(-\Delta \Delta \mathrm{CT})$ method. Methods 25: 402-408, 2001.

23. Yeh CC, Hou MF, Wu SH, et al: A study of glutathione status in the blood and tissues of patients with breast cancer. Cell Biochem Funct 24: 555-559, 2006.

24. Kasapović J, Pejić S, Todorović A, et al: Antioxidant status and lipid peroxidation in the blood of breast cancer patients of different ages. Cell Biochem Funct 26: 723-730, 2008.

25. Fernandes RC, Bevilacqua JL, Soares IC, et al: Coordinated expression of ER, PR and HER2 define different prognostic subtypes among poorly differentiated breast carcinomas. Histopathology 55: 346-352, 2009.

26. Basu S, Chen W, Tchou J, et al: Comparison of triple-negative and estrogen receptor-positive/progesterone receptor-positive/ HER2-negative breast carcinoma using quantitative fluorine-18 fluorodeoxyglucose/positron emission tomography imaging parameters: a potentially useful method for disease characterization. Cancer 112: 995-1000, 2008.

27. Murawaki Y, Tsuchiya H, Kanbe T, et al: Aberrant expression of selenoproteins in the progression of colorectal cancer. Cancer Lett 259: 218-230, 2008.

28. Li S, Yan T, Yang JQ, et al: The role of cellular glutathione peroxidase redox regulation in the suppression of tumor cell growth by manganese superoxide dismutase. Cancer Res 60 : 3927-3939, 2000.
29. Estrela JM, Ortega A and Obrador E: Glutathione in cancer biology and therapy. Crit Rev Clin Lab Sci 43: 143-181, 2006.

30. Gaudiano G, Koch TH, LoBello M, et al: Lack of glutathione conjugation to adriamycin in human breast cancer MCF-7/DOX cells. Inhibition of glutathione S-transferase p1-1 by glutathione conjugates from anthracyclines. Biochem Pharmacol 60: 1915-1923, 2000

31. Ozkan A and Fiskin K: Protective effect of antioxidant enzymes against drug cytotoxicity in MCF-7 cells. Exp Oncol 28: 86-88, 2006.

32. Ilvasova D, Mixon G, Wang F, et al: Markers of oxidative status in a clinical model of oxidative assault: a pilot study in human blood following doxorubicin administration. Biomarkers 14 : 321-325, 2009.

33. Han XQ, Li ZH, Zhang JG, et al: Effect of decreased GSH on sensitivity of breast cancer cells to ADM. Sichuan Da Xue Xue Bao Yi Xue Ban 36: 770-774, 2007 (In Chinese).

34. Vibet S, Goupille C, Bougnoux P, et al: Sensitization by docosahexaenoic acid (DHA) of breast cancer cells to anthracyclines through loss of glutathione peroxidase (GPx1) response. Free Radic Biol Med 44: 1483-1491, 2008.

35. Sun W, Kalen AL, Smith BJ, et al: Enhancing the antitumor activity of adriamycin and ionizing radiation. Cancer Res 69: 4294-4300, 2009.

36. Di X, Shiu RP, Newsham IF and Gewirtz DA: Apoptosis, autophagy, accelerated senescence and reactive oxygen in the response of human breast tumor cells to adriamycin. Biochem Pharmacol 77: 1139-1150, 2009. 